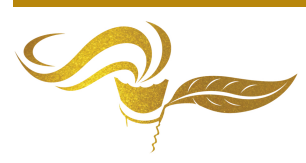

\title{
Impact of COVID-19 Pandemic in Turkey
}

\section{N. Tug̃ay Güven and E. özturk Işik}

Institute of Biomedical Engineering of Bogaziçi University, Istanbul, Turkey.

* Correspondence: Email:tugayilyasoglu@gmail.com

Received 12 December, 2020; Revised 8 January, 2021; Accepted 11 January, 2021

Available online 12 January, 2021 at www.atlas-journal.org, doi: 10.22545/2021/00147

\section{Short Letter}

Turkey is one of the countries affected by the COVID-19 outbreak relatively late with the first positive case reported on March 10, 2020. Following the first incident, COVID-19 cases escalated quickly and dramatically. As of December 10, 2020, Turkey's number of new cases was 30.424, which is fourth amongst all the countries, following highly populated countries like the USA, Brazil and India. Additionally, the total number of cases in Turkey since the beginning of the pandemic has reached 1.748.567 with a death toll of 15.751 (Turkish Ministry of Health, 2020 [1]).

Turkish Ministry of Health was quick in its response to the pandemic. Only a week after the first incident, the schools and universities were suspended. The restaurants, cafes, museums, shopping malls, hairdressers, nightclubs and wedding halls were temporarily closed. Wearing a mask in public places has become mandatory. Additionally, flexible working hours and shifts were adopted. Although a total lock down was never applied because of economical reasons, curfews during the weekends and holidays have become the standard.

In addition to these policies, a unique age selected curfew was adopted. Turkey is a relatively young country, with a population of 25.5 million children and adolescents while only 7.5 million people are over 65 (Turkish Statistical Institute, 2020 [2]). Turkey decided to and applied a strict curfew for these two age groups; elderly people aged over 65 as they have higher morbidity risk and youngsters aged under 20 as they have a higher chance of spreading the virus without showing any symptoms. Additionally, the youngsters and the elderly are mostly out of the work force, therefore their curfew has not affected the economy. Although in theory it is a very bright idea to lockdown $40 \%$ of the population, the isolation of these two age groups actually requires a special attention.

Geriatricians recommend regular social and physical activity for cognitive and emotional well being of the elderly (Soysal, Aydin, \& Isik, 2020 [3]). Curfew interrupted their physical and social activities and has the potential of affecting them negatively both psychologically and physically in the long run.

On the other hand, COVID-19 changed daily lives of adolescents drastically all over the world. A comparative study between Turkish and Danish adolescents' feelings indicated that Turkish adolescents were significantly more concerned about their future with it getting worse with the pandemic $(61,4 \%$ vs 
$22.8 \%$ ) along with worsening feelings of boredom of life. It is discussed that this dramatic difference might be the result of different pandemic measures between the countries such as the curfew. In addition to that Turkish students, even the ones attending private schools, were less likely to have technological equipment and encountered internet connection problems more frequently compared to Danish students (Seyahi, Ozcan, Sut, Mayer, \& Poyraz, 2020 [4]). This by itself is a major concern for their future, especially when disadvantaged adolescents who live in far east villages of the country without any internet connection to attend classes is considered. On the other hand, it is suggested that curfew for adolescents in Turkey is a serious matter that has to be discussed in terms of developmental perspective as well. Adolescence is a time when teens have to go out and explore the world in order to develop a sense of self and independence.

There is a risk of adolescents perceiving this curfew period as a suppression of their will while rest of the population has the license to go out and work (Kanbur \& Akgul, 2020 [5]).

In conclusion, Turkey is going through a rough time as the rest of the world and is not an exception in terms of increased symptoms of anxiety, depression, post-traumatic stress disorder and stress during the COVID-19 pandemic in the general population (Ustun, 2020 [6]); (Kazan Kizilkurt, Yilmaz, Noyan, \& Dilbaz, 2020 [7]); (Xiong et al., 2020 [8]). Nevertheless this age-selected curfew and isolating them from the society, without any compensation mechanisms, might have severe future implications on the psychosocial development, education and psychological wellbeing of adolescents in addition to increased cognitive and physical impairments of elderly that has to be monitored in years to come. Although questions are way more than the answers about the future of Turkey, the answers are not yet to come.

\section{References}

[1] Turkish Ministry of Health. (2020). COVID-19 Information Page. Retrieved from https://covid19.saglik.gov.tr/

[2] Turkish Statistical Institute. (2020). Population Statistics. Retrieved from http://www.turkstat.gov.tr/UstMenu.do?metod1/4temelist

[3] Soysal, P., Aydin, A. E., \& Isik, A. T. (2020). Challenges experienced by elderly people in nursing homes due to the coronavirus disease 2019 pandemic. Psychogeriatrics, 20(6), 914-915. doi:10.1111/psyg.12620

[4] Seyahi, L. S., Ozcan, S. G., Sut, N., Mayer, A., \& Poyraz, B. C. (2020). doi:10.1101/2020.10.21.20217406

[5] Kanbur, N., \& Akgul, S. (2020). Quaranteenagers: A Single Country Pandemic Curfew Targeting Adolescents in Turkey. J Adolesc Health, 67(2), 296-297. doi:10.1016/j.jadohealth.2020.05.007

[6] Ustun, G. (2020). Determining depression and related factors in a society affected by COVID-19 pandemic. Int J Soc Psychiatry, 20764020938807. doi:10.1177/0020764020938807

[7] Kazan Kizilkurt, O., Yilmaz, A., Noyan, C. O., \& Dilbaz, N. (2020). Health anxiety during the early phases of COVID-19 pandemic in Turkey and its relationship with postpandemic attitudes, hopelessness, and psychological resilience. Perspect Psychiatr Care. doi:10.1111/ppc.12646

[8] ). Impact of COVID-19 pandemic on mental health in the general population: A systematic review. J Affect Disord, 277, 55-64. doi:10.1016/j.jad.2020.08.001

Funding: This short letter received no external funding.

Conflicts of Interest: The authors declares no conflict of interest.

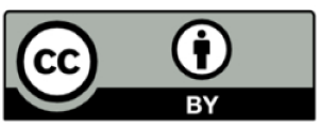

Copyright (C) 2021 by the authors. This is an open access article distributed under the Creative Commons Attribution License (https://creativecommons.org/licenses/by/4.0/), which permits unrestricted use, distribution, and reproduction in any medium, provided the original work is properly cited. 


\section{About the Authors}

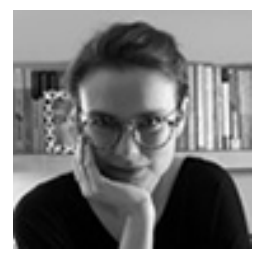

N. Tug̃gay Güven graduated from Istanbul Bilgi University, Istanbul, Turkey in 2004 with a Bachelor's degree in Psychology. She received her first Master's degree from the Psychological Sciences program of Bogazici University, Istanbul, Turkey in 2007 and her second Master's degree from Advertisement and Publicity program of Marmara University, Istanbul, Turkey in 2011. She has been doing her Ph.D. on Biomedical Engineering program of Bogazici University, Istanbul, Turkey since 2013 and is a Ph.D. candidate. Her current research interests include adoption of novel magnetic resonance imaging techniques to multiple sclerosis disease in order to understand the underlying mechanisms of the disease and increase patients' life quality in the long run.

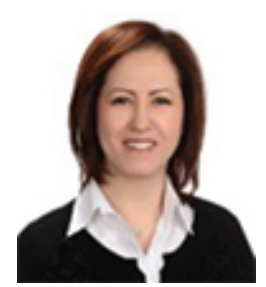

Dr. Esin Özturk Işik is Associate Professor and Director of Computational Imaging Laboratory at the Institute of Biomedical Engineering of Bogaziçi University, Istanbul, Turkey. She has been conducting research in the field of magnetic resonance imaging (MRI). The main aim of her projects has been developing novel molecular magnetic resonance imaging techniques to allow for a better understanding of underlying biochemistry of diseases in order to improve patient health. The technical projects at her laboratory has focused on designing new algorithms for molecular MR imaging data acquisition, post-processing and quantitation, as well as biostatistical analysis. Her laboratory has also worked on developing computational methods based on machine learning for MR image analysis for understanding disease mechanisms. Another focus of technical projects has been developing novel quantitative molecular MR imaging methodologies for fast and accurate data acquisition and processing. She has worked on translating all the projects developed at her laboratory into the clinics in collaboration with the clinical investigators for the benefit of the patients. The projects she has proposed have focused on brain tumors, prostate cancer, and breast cancer, with the overarching goal of studying metabolism in various human systems.

Her Educational background is: Ph.D. University of California at Berkeley and University of California at San Francisco. Joint Graduate Program in Bioengineering (August 2002-March 2007), M.S. University of Alabama at Birmingham. Biomedical Engineering (September 1999-December 2001), and B.S. Middle East Technical University, Ankara, Turkey. Computer Engineering (September 1995-June 1999). 